\title{
Case Report: Radiological Features of Paraquat Herbicide Poisoning: A Case Report
}

\author{
Khosrow Agin $^{1 *}$ Q, Shahin Shadnia ${ }^{2}$, Babak Mostafazadeh ${ }^{3}$
}

1. Department of Cardiovascular and Pulmonology, Loghman Hakim Hospital, School of Medicine, Shahid Beheshti University of Medical Sciences, Tehran, Iran.

2. Department of Clinical Toxicology, Loghman Hakim Educational Hospital, School of Medicine, Shahid Beheshti University of Medical Sciences, Tehran, Iran.

3. Department of Forensic Medicine, Loghman Hakim Educational Hospital, School of Medicine, Shahid Beheshti University of Medical Sciences, Tehran, Iran.

\begin{tabular}{|c|c|}
\hline 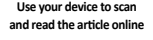 & tafazadeh B. Radiological Features of Paraquat Herbicide Poisoning: A Case Report. Interna- \\
\hline 口象为回 & al of Medical Toxicology and Forensic Medicine. 2019; 9(2):97-99. https://doi.org/10.32598/jimtfm.v9i2.25044 \\
\hline 咧 & d d) https://doi.org/10.32598/ijmtfm.v9i2.25044 \\
\hline
\end{tabular}

\section{(a) 03}

Article info:

Received: 12 Oct 2018

First Revision: 03 Nov 2018

Accepted: 09 Feb 2019

Published: 01 Apr 2019

Keywords:

Paraquat, Poisoning, CT

Imaging, Chest Xray, Iran

\section{ABSTRACT}

Paraquat (PQ) is a herbicide with potent toxicity. The most frequent human poisoning occurs by ingestion and inhalation. Its clinical feature includes pulmonary edema in the first 48 hours post-toxicity with progression to acute respiratory distress syndrome. A 50-year-old male poisoned patient referred to the emergency department with the complaint of shortness of breath. His companions had an herbicide poison bottle. Respiratory failure gradually intensified. The patient was intubated and under mechanical ventilation for one month. kidney and liver insufficiency were gradually added to the patient's clinical feature in the following days. He died with multiorgan failures one month later. Standard chest X-ray is not beneficial for assessing PQ intoxication. High resolution computed tomography scan is recommended at day 7 post-ingestion for evaluating PQ poisoning.

\section{Introduction}



araquat (PQ) is a known bipyridyl compound with worldwide general use and non-selective herbicidal properties. The PQ was first used in 1962. It has favorable characteristics for farmers with broadspectrum effects, including inactivation in contact with soil and rain-fed washing [1]. The annual ingestion in- toxication of it is reported as 2000 cases with a high mortality rate (60-70\%) in the Asian countries [2].

\section{Case Report}

A 50-year-old male poisoned patient referred to the emergency department with the complaint of shortness of breath. His companions had an herbicide poison bottle. The chemical name of that poison was PQ. The patient was admitted to the intensive care unit. Physical

\section{* Corresponding Author:}

Khosrow Agin, MD.

Address: Department of Heart and Pulmonology, Loghman Hakim Hospital, School of Medicine, Shahid Beheshti University of Medical Sciences,

Tehran, Iran.

Tel: +98 (912) 1170019

E-mail: khosrow.agin@yahoo.com\&Agin@sbmu.ac.ir 


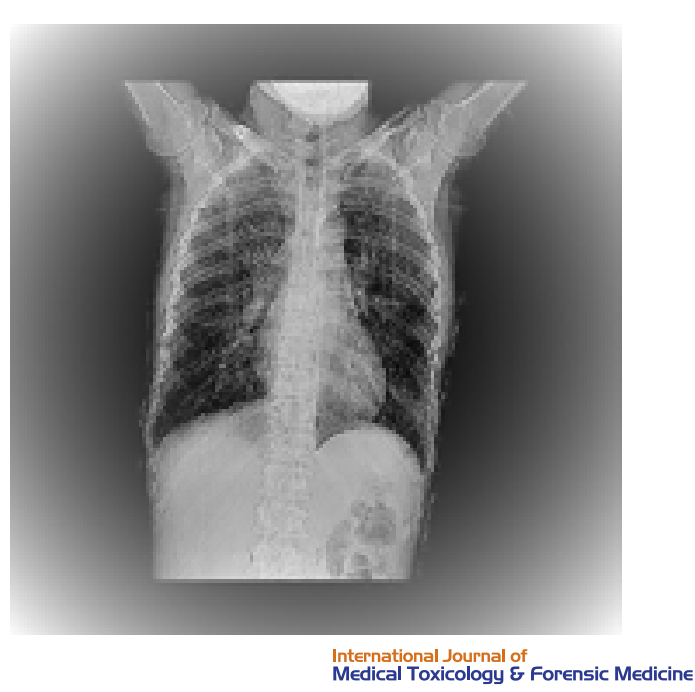

Figure 1. Chest $\mathrm{X}$-ray radiography

examinations revealed agitation and tachypnea; $\mathrm{RR}=24$ / minute, $\mathrm{PR}=124 /$ minute, $\mathrm{BP}=150.95 \mathrm{mmHg}, \mathrm{T}=38.4$ ${ }^{\circ} \mathrm{C}$, and Pulse oximeter $\mathrm{O}_{2}$ sat $=75 \%$. Chest examination presented rhonchi, rale and coarse crackle in the base of both lungs. The early blood biochemistry evaluation suggested $\mathrm{WBC}=16000 \mu / \mathrm{mL}$ and the other obtained biochemistry laboratory data were in the normal range. The hemoperfusion was performed in the next 24 hours. Respiratory failure gradually intensified. The patient was intubated and under mechanical ventilation for one month. kidney and liver insufficiency were gradually added to the patients' clinical features in the following days. He died with multiorgan failures one month later.

\section{Discussion}

PQ herbicide is still used with easy accessibility in Iran. The rate of suicide attempts with PQ is significant with a mortality rate of $39.6 \%$ [3] in the Iranian population and $60-70 \%$ in the Asian countries [4]. PQ ingestion is the main means of human intoxication. Lung and kidney are the most frequent targets of toxicants. The PQ concentration in the lung parenchymal is several times higher than the plasma level in early poisoning.

Standard chest X-ray is not useful in the evaluation of PQ intoxication. It has low sensitivity and specificity. Chest radiographic features indicated bilateral shadows made of ground glass opacity. It is distributed in the center of the lung. Figure 1 reveals the studied patient's chest X-ray radiography. However, diffuse consolidation and pneumomediastinum associated with pneumothorax may be detected [5]. A high-risk radiologic manifestation is usually observed in the first two weeks post-poisoning as pneumothorax, pneumomediastinum, and ARDS. The fibrosis usually appears in a radiology image at about 2-4 weeks post-exposure [6].

A high resolution Computed Tomography (CT) scan is recommended at day 7 post-ingestion for PQ poisoning [7]. The classic sign of CT scan manifestation is the fine fibrosis in the middle and central areas of the lung parenchyma; it is tenderly progressed in a wedge shape toward the hilum [3]. The manifestations of a CT scan can help in the prognostic assessment. The features of ground glass and consolidation are associated with a poor prognosis in an early CT scan [8]. Figure 2 shows the characteristics of the CT Scan manifestations of PQ poisoning.



B

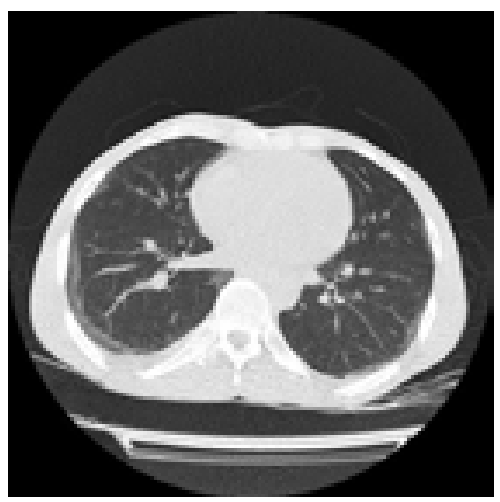

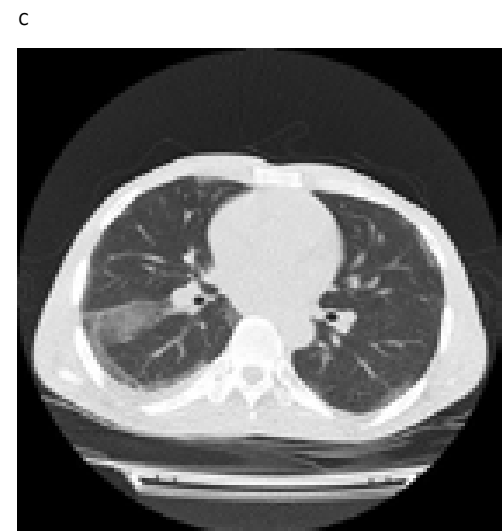
International Journal of
Medical Toxicology \& forensic Medicine

Figure 2. CT Scan manifestation of paraquat poisoning 


\section{Conclusion}

Standard chest X-ray is not beneficial for assessing PQ intoxication. High-resolution CT scan is recommended at day 7 post-ingestion for evaluating PQ poisoning.

\section{Ethical Considerations}

\section{Compliance with ethical guidelines}

All ethical principles were considered in this article. The participants were informed about the purpose of the research and its implementation stages; they were also assured about the confidentiality of their information; Moreover, They were allowed to leave the study whenever they wish, and if desired, the results of the research would be available to them.

\section{Funding}

This research did not receive any specific grant from funding agencies in the public, commercial, or not-forprofit sectors.

\section{Authors' contributions}

Data gathering of the patient: Shahin Shania; The initial draft: Babak Mostafazadeh; and Final edited, discussion and corresponding: Khosrow Agin.

\section{Conflict of interest}

The authors declared no conflict of interest.

\section{Acknowledgements}

The author thank the poisoning center of the Loghman Hakim hospital for providing patients' information to the current research.

\section{References}

[1] Wikipedia. Paraquat. [Internet]. 2019 [Updated 2019 April 8]. Available from: https://en.wikipedia.org/wiki/Paraquat

[2] Seok SJ, Gil HW, Jeong DS, Yang JO, Lee EY, Hong SY. Paraquat intoxication in subjects who attempt suicide: Why they chose paraquat. The Korean Journal of Internal Medicine. 2009; 24(3):247-51. [DOI:10.3904/kjim.2009.24.3.247]

[3] Jamshidi F, Fathi G, Davoodzadeh H. [Investigation Paraquat Poisoning in Southwest of Iran- from sign to mortality and morbidity (Polish)]. Archives of Forensic Medi- cine and Criminology. 2017; 67(1):35-45. [DOI:10.5114/ amsik.2017.70336]

[4] Gil HW, Hong JR, Jang SH, Hong SY. Diagnostic and therapeutic approach for acute paraquat intoxication. The Korean Journal of Internal Medicine. 2014; 29(11):1441-9. [DOI:10.3346/jkms.2014.29.11.1441]

[5] Im JG, Lee KS, Han MC, Kim SJ, Kim IO. Paraquat poisoning: findings on chest radiography and CT in 42 patients. American Journal of Roentgenology. 1991; 157(4):697-701. [DOI:10.2214/ajr.157.4.1892020]

[6] Kavousi-Gharbi S, Jalli R, Rasekhi-Kazerouni A, Habibagahi Z, Marashi SM1. Discernment scheme for paraquat poisoning: A five-year experience in Shiraz, Iran. World Journal of Experimental Medicine. 2017; 7(1):31-9. [DOI:10.5493/wjem. v7.i1.31]

[7] Zhang H, Liu P, Qiao P, Zhou J, Zhao Y, Xing X, et al. CT imaging as a prognostic indicator for patients with pulmonary injury from acute paraquat poisoning. The British Journal of Radiology. 2013; 86(1026):20130035. [DOI:10.1259/ bjr.20130035]

[8] Kang X, Hu DY, Li CB, Li XH, Fan SL, Liu Y, et al. The volume ratio of ground glass opacity in early lung $\mathrm{CT}$ predicts mortality in acute paraquat poisoning. PLOS One. 2015; 10(4):e0121691. [DOI:10.1371/journal.pone.0121691] 